\title{
Neurocirugía en paciente despierto y su manejo intraoperatorio: Reporte de caso.
}

\author{
Jaremko S. ${ }^{1}$, Campoy F. ${ }^{1}$, Mazzoleni A. ${ }^{1}$, Estanga S. ${ }^{1}$, Guarrera P. ${ }^{1}$, García Picasso D. ${ }^{1}$, Daud O. ${ }^{1}$
}

1 Hospital Bernardino Rivadavia, Ciudad autónoma de Buenos Aires, Argentina.

Introducción: La neurocirugía con paciente despierto es una práctica que existe hace más de 50 años, cada vez más segura. Sus beneficios son posibilitar una resección más amplia de la lesión con mejor sobrevida, y disminución del daño neurológico postquirúrgico, del tiempo de hospitalización, del costo, y de complicaciones postoperatorias.

Descripción del caso: Paciente femenino, 62 años, $70 \mathrm{~kg}$, 1,60 metros. Presenta meningioma recidivado, con afectación motora del hemicuerpo izquierdo.

En el acto quirúrgico se realiza sedoanalgesia, monitoreo de PANI, ECG, oximetría de pulso y capnografía a través de cánula nasal de oxígeno, dos accesos venosos periféricos (18 y 16 G). Premedicación: $150 \mathrm{mcg}$ de fentanilo y $2 \mathrm{mg}$ de midazolam. Se coloca catéter en arteria radial izquierda para medición de presión invasiva. Se infunde propofol $2 \mathrm{mg} /$ $\mathrm{kg} / \mathrm{h}$ y dexmedetomidina $0,04 \mathrm{mcg} / \mathrm{kg} / \mathrm{h}$.

Siendo el bloqueo de los nervios del scalp esencial para la analgesia, los neurocirujanos la realizaron con $30 \mathrm{ml} \mathrm{de}$ bupivacaína con epinefrina $0,25 \%$ + lidocaína con epinefrina $1 \%$. Luego se colocó cabezal de Mayfield previa infiltración.

La paciente mantuvo ventilación espontánea y respuesta al estímulo durante todo el procedimiento. Las infusiones de propofol y dexmedetomidina se suspendieron 15 minutos previos al mapeo cortical funcional (con estimulación directa), para luego reiniciar infusión de propofol hasta el final de la cirugía.

Información adicional: Cabe remarcar las consideraciones preanestésicas y la selección de pacientes, clave en el éxito del procedimiento. El exámen físico debe enfocarse en la vía aérea, ya que parámetros de vía aérea dificultosa podrían contraindicar el procedimiento por su alto riesgo al momento de perder la ventilación espontánea. Debe considerarse el perfil psicológico y la capacidad de comprensión y cooperación del paciente.

Discusión: Dentro de las complicaciones más frecuentes en el intraoperatorio están las convulsiones, la depresión respiratoria, nauseas y vómitos, déficit motor y el dolor.

El manejo de la analgesia representa un desafío cuando está relacionado con la estimulación de áreas de rica inervación como las meninges donde no es posible infiltrar con anestésico local. Por lo tanto, el único recurso disponible es la analgesia endovenosa. Sin embargo, el riesgo latente de apnea, especialmente con la utilización de opioides hace necesaria la utilización de otros agentes analgésicos y coadyuvantes.

Mientras nosotros elegimos una técnica de sedación consciente durante todo el procedimiento, los distintos anestesiólogos tienen sus prácticas preferidas para este procedimiento, entre ellas anestesia local, técnicas de dormidodespierto-dormido y dormido-despierto. Ninguna ha demostrado ser superior.

https://doi.org/10.25237/congresoclasa2019.44 